\title{
Cytotoxicity of nanoparticles independent from oxidative stress
}

\author{
Eleonore Fröhlich ${ }^{1,2}$, Claudia Samberger ${ }^{1,2}$, Tatjana Kueznik', Markus Absenger1, \\ Eva Roblegg ${ }^{3}$, Andreas Zimmer ${ }^{3}$ and Thomas R. Pieber ${ }^{2}$ \\ ${ }^{1}$ Center for Medical Research, Medical University of Graz, Stiftingtalstr 24, A-8010 Graz, Austria \\ ${ }^{2}$ Department of Internal Medicine, Division of Endocrinology and Nuclear Medicine, Medical University of Graz, \\ Auenbruggerplatz 15, A-8036 Graz, Austria \\ ${ }^{3}$ Institute of Pharmaceutical Sciences, Department of Pharmaceutical Technology, Karl-Franzens-University of Graz, \\ Universitätsplatz 1, A-8010 Graz, Austria
}

(Received February 28, 2009; Accepted May 11, 2009)

\begin{abstract}
The use of nano-sized materials offers exciting new options in technical and medical applications. On the other hand, adverse effects on cells have been reported and may limit their use. In addition to physico-chemical parameters such as contamination with toxic elements, fibrous structure and high surface charge, the generation of radical species was identified as key mechanism for cytotoxic action of nanoparticles. The cytotoxic potential of nanoparticles in the absence of radical generation is less well investigated. This study aims to investigate the size-dependent effect of carboxyl polystyrene particles on cells to identify potential adverse effects of these particles. Particles were characterized in different solutions to assess the influence of the medium on size and surface charge. Viability, membrane integrity, apoptosis, proliferation and generation of oxidative stress were investigated. In addition the intracellular localization of the particles was recorded. $20 \mathrm{~nm}$ polystyrene particles induced cellular damage by induction of apoptosis and necrosis. These particles generated radicals to the same degree as larger polystyrene particles. Particles were taken up into endosomes and lysosomes in a size-dependent manner. Protein containing solutions led to increases in particle size, decreased cytotoxicity and reduced cellular uptake. It can be concluded that even in the absence of high surface reactivity and not linked to the generation of radicals nano-sized particles may cause cell damage. The mechanism of this damage includes apoptosis, necrosis and inhibition of proliferation.
\end{abstract}

Key words: Nanotoxicology, Cytotoxicity, Nanoparticles, Subcellular localization, Apoptosis

\section{INTRODUCTION}

Nano-sized materials are increasingly used in technical and medical applications and it is expected that in the future the use of nanotechnology will further increase. On the other hand there is concern that this technology may also present a risk for health of users and producers of these particles. This concern is based on the finding that nano-sized particles differ from bulk materials regarding many physicochemical and biological properties and that several nanoparticles, which could be used in medical applications, act cytotoxic (Lewinski et al., 2008). Plain nano-sized gold particles for instance show sizedependent organ distribution and cytotoxic effects (Pan et al., 2007; Semmler-Behnke et al., 2008). In addition to size the coating has a pronounced influence on biocompatibility: This effect has been studied systematically for poly(amidoamine) polymers by Boas et al. (2006). Systematic studies, however, are difficult because changes in surface charge are often accompanied by changes in size and/or hydrophobicity and therefore a combined effect is evaluated. In addition, often the effect of surface charges can be evaluated in single particles because aggregation occurs.

Polystyrene particles are widely used as model and reference particles to study cellular uptake (Panyam et al., 2002; Rejman et al., 2004), as well as for in-vitro (Geiser et al., 2005; Olivier et al., 2003; Papageorgiou et al., 2007) and for in-vivo studies (Brown et al., 2001; Demoy et al., 1997; Fernandez-Urrusuno et al., 1995; Gibaud et

Correspondence: Eleonore Fröhlich (E-mail: eleonore.froehlich@klinikum-graz.at) 
al., 1996; Kanai et al., 1996; Kato et al., 2003; Nemmar et al., 2002; Silva et al., 2005; Yacobi et al., 2008). Polystyrene is not cytotoxic and the spheres are commercially available in reproducible sizes and surface charges. For the assessment of size it is fortunate that all particles independent of their sizes possess the same surface charge. When working with nanoparticles the interaction with proteins especially from blood or from epithelial mucous is important. The change of particle characteristics from suspension in distilled water or in buffer to suspension in cell culture medium with serum albumin is only recently been taken into account. The binding of proteins to nanoparticles called 'protein corona' determines the biological effects of the particles to a great extent. Surprisingly, even particles of different sizes made from the same material and having the same surface charge display a corona with different composition (Lundqvist et al., 2008).

The mechanism of cell damage of nanoparticles generally is explained by the generation of radicals through a large catalytic surface (Nel et al., 2006). Several types of nanoparticles like for instance metal oxides generate oxidative stress in cells (Limbach et al., 2007; Park et al., 2008). In many cases the generation of oxidative stress can be demonstrated also in the absence of cells (Xia et al., 2006). Polystyrene particles, with the exception of strongly cationic ones, allow the evaluation of cell damage in the absence of oxidative stress because these particles appear to induce radicals only in professional phagocytes such as macrophages but not in the absence of cells (abiotic condition, Xia et al., 2006) and in non-phagocytotic cells (Swain et al., 2004).

This study was conducted to find out if polystyrene particles can induce cell damage independent from generation of oxidative stress. Further, we examined i) at which size cytotoxicity is observed, ii) how the presence of serum proteins changed the cytotoxic effect, iii) which mechanisms of the cell damage were involved, iv) if cytotoxicity is correlated to the ability to produce radicals and v) if cytotoxicity was correlated to uptake into specific organelles.

\section{MATERIALS AND METHODS}

\section{Particles}

Carboxyl polystyrene latex beads in sizes of 2040-60-140-200-500 nm, $20 \mathrm{~nm}$ carboxylate-modified polystyrene latex beads and $200 \mathrm{~nm}$ amidine polystyrene latex beads were obtained from Invitrogen. For cellular uptake studies yellow-green (505/515) fluorescently labelled carboxyl PS particles in sizes of 20, 40 and $200 \mathrm{~nm}$ and red (580/605) fluorescent- ly labeled carboxyl PS particles in nominal sizes of 20, 40 and $200 \mathrm{~nm}$ (FluoSpheres, Invitrogen, Lofer, Austria) were used. $200 \mu \mathrm{M} \mathrm{H}_{2} \mathrm{O}_{2}$ and $500 \mu \mathrm{g} / \mathrm{ml}$ quartz particles (BCR66, size standard particles, $1 \mu \mathrm{m}$, Duke Scientific, Fremond, CA, USA) served as positive controls.

Physico-chemical characterization of particles was performed by dynamic light scattering using a Malvern Zetasizer 3000 HS. For the measurements particles were diluted with the respective medium to concentrations less than $1 \mathrm{mg} / \mathrm{ml}$ and sonicated for $20 \mathrm{~min}$. After equilibration of the sample solution to $25^{\circ} \mathrm{C}$ size and zeta potential were measured at $633 \mathrm{~nm}$ and a detection angle of $90^{\circ}$. For sample analysis nonnegative least-squares (NNLS) software was used.

\section{Cell culture}

The human endothelial cell line EAhy926 (kind gift from Dr. C.J. Edgell) was cultured in Dulbecco's modified Eagle's medium (DMEM), 10\% fetal bovine serum (FBS), 2 mM L-glutamine and 1\% penicillin/streptomycin. Cells were cultured at $37^{\circ} \mathrm{C}$ in a humid $95 \%$ air/ $5 \% \mathrm{CO}_{2}$ atmosphere. Cells were pre-cultured in this medium $24 \mathrm{hr}$ before treatment.

Cells were exposed to the particles in concentrations of 500-250-125-62.5 and $31.25 \mu \mathrm{g} / \mathrm{ml}$. The particles were suspended in DMEM with $0 \%, 1 \%, 5 \%$ and $10 \%$ FBS to evaluate the influence of protein on the biological effect. All particle suspensions were sonicated for $20 \mathrm{~min}$ before addition to the cells. Exposures were performed at $37^{\circ} \mathrm{C}$ in a $95 \%$ air $/ 5 \% \mathrm{CO}_{2}$ atmosphere and two time points (4 $\mathrm{hr}$ and $24 \mathrm{hr}$ ) were evaluated.

\section{Screening assays}

For the determination of ATP-content the CellTiter-Glo Luminescent Cell Viability Assay (Promega, Mannheim, Germany) was used according to the manufacturer's instruction and luminescence was read on a Lumistar (BMG Labtech, Offenburg, Germany).

For Neutral Red uptake the assays kit Neutral red for 1,200 tests without microplates (Aniara Corporation, Mason, OH, USA), for formazan bioreduction CellTiter $96{ }^{\circledR}$ AQueous Non-Radioactive Cell Proliferation Assay (Promega) and for protein content (sulforhodamine B staining) the Invitro Toxicology assay kit Sulforhodamine B Based (TOX-6 assay, Sigma-Aldrich, Wien, Austria) was used. Absorbance was read at $690 \mathrm{~nm}$ for Neutral Red uptake, at $490 \mathrm{~nm}$ for formazan bioreduction and at $565 \mathrm{~nm}$ for the sulforhodamine B staining on a SPECTRA MAX plus 384 (Molecular Devices). 
Cytotoxicity of nanoparticles

\section{Protein content (leucin uptake)}

$1 \mu \mathrm{Ci}$ methyl- ${ }^{3} \mathrm{H}$ Leucine (GE Healthcare, Wien, Austria) was added $4 \mathrm{hr}$ prior to cell harvesting with a 96 filter plate FilterMate Cell Harvester (Perkin Elmer) on filter plates (Unifilter-96 GF/C white 96 well plates + foil from, Perkin Elmer). Filter plates were air-dried overnight and covered with sealing foil at the backside of the plate. $20 \mu 1$ Scintillation Cocktail (Betaplate Scint, Perkin Elmer) was added to each well and the plates covered with a clear sealing foil to prevent drying up. Scintillation was read at a Wallac Trilux Beta counter (Perkin Elmer).

\section{Calcein AM/ Ethidium homodimer (EthD-1) staining}

Cells were seeded in chamber slides (BD-Falcon) and cultured $24 \mathrm{hr}$ prior to the actual experiment. After medium change PS particles were added and cells cultured for additional $24 \mathrm{hr}$. Medium was discarded and walls removed from the chamber slide. LIVE/DEAD Viability/Cytotoxity Kit for mammalian cells (Invitrogen) at 5 $\mu \mathrm{M}$ concentration was used and cells were incubated for 30 min at RT in the dark. After washing with PBS, pictures were taken with a confocal laser scanning microscope LSM510 Meta (Zeiss, Wien, Austria). Images were acquired at $488 \mathrm{~nm}$ excitation wavelength using a BP 505-530 nm band-pass detection filter for the green channel (Calcein AM) and $543 \mathrm{~nm}$ excitation wavelength in conjunction with LP 560 for the red channel (EthD1). For quantification on a fluorometer cells were seeded in plates and fluorescence was read at Ex/Em wavelength of 485/520 nm for Calcein AM and 544/612 nm for EthD-1 staining at a fluorometer (FLUOstar Optima, BMG Labtech).

\section{Proliferation}

\section{Thymidine uptake}

$1 \mu \mathrm{Ci}$ methyl- ${ }^{3} \mathrm{H}$ Thymidine (GE Healthcare, Wien, Austria) was added $4 \mathrm{hr}$ prior to cell harvesting with a 96 filter plate FilterMate Cell Harvester (Perkin Elmer) on filter plates (Unifilter-96 GF/C white 96 well plates + foil from, Perkin Elmer). Filter plates were air-dried overnight and covered with sealing foil at the backside of the plate. $20 \mu 1$ Scintillation Cocktail (Betaplate Scint, Perkin Elmer) was added to each well and the plates covered with a clear sealing foil to prevent drying up. Scintillation was read at a Wallac Trilux Beta counter (Perkin Elmer).

\section{BrdU-uptake}

Cells were seeded in chamber slides (BD-Falcon) and cultured $24 \mathrm{hr}$ prior to the actual experiment. Cells were treated for $24 \mathrm{hr}$ with PS particles in total; for the last 4 hr $10 \mu \mathrm{M}$ BrdU (Roche Diagnostics, Wien, Austria) was added. Medium was discarded and walls removed from the chamber slide. Cells were fixed for $10 \mathrm{~min}$ in absolute methanol at $-20^{\circ} \mathrm{C}$ and for $3 \mathrm{~min}$ in acetone. Slides were washed three times with PBS at RT and subsequently incubated with Anti-BrdU AlexaFluor488-labelled antibody (mouse, 1:40, Invitrogen) for $30 \mathrm{~min}$. Slides were rinsed again $3 \times 5 \mathrm{~min}$ in PBS and nuclei counterstained with $0.5 \mu \mathrm{g} / \mathrm{ml}$ propidium iodide (Invitrogen) for $30 \mathrm{~min}$ at RT. Slides were viewed at the confocal laser scanning microscope LSM510 Meta (Zeiss). Images were acquired at $488 \mathrm{~nm}$ excitation wavelength using a BP $505-530 \mathrm{~nm}$ band-pass detection filter for the green channel (BrdU) and $543 \mathrm{~nm}$ excitation wavelength in conjunction with LP 560 for the red channel (propidium iodide).

\section{Apoptosis}

\section{Caspase 3/7 activation}

Activation was determined using Caspase-Glo 3/7 Assay (Promega) according to the instruction manual and luminescence read on a Lumistar (BMG Labtech).

\section{TUNEL}

For the detection of double-strand breaks the APOBrdUTM TUNEL Assay Kit (Invitrogen) was used according to the instructions in the manual. Cells were treated in chamber slides. Slides were viewed at the confocal laser scanning microscope LSM510 Meta (Zeiss). Settings were the same as for BrdU-uptake.

\section{YoPro-1/propidium iodide staining}

The Vybrant Apoptosis Assay Kit \#4 (Invitrogen) composed of $100 \mu \mathrm{Y}$ YO-PRO-1 and $1.5 \mathrm{mM}$ propidium iodide was used according to the instructions in the manual. Cells were treated in chamber slides and viewed at the confocal laser scanning microscope LSM510 Meta (Zeiss). Settings were the same as for BrdU-uptake.

\section{Detection of cleaved cytokeratin 18}

Cells were treated in chamber slides for microscopy. After treatment, cells were washed with PBS. After fixation with methanol at $-20^{\circ} \mathrm{C}$ for $30 \mathrm{~min}$ and three rinses in PBS, cells were incubated with M30 Cyto Death ALX-804-590 antibody (Eubio, Wien, Austria, 1:100) for $30 \mathrm{~min}$ at RT. For negative controls mouse IgG (Linaris Biologische Produkte, Wertheim-Bettingen, Germany, 1:1000) was used. Subsequently, slides were rinsed in PBS ( $3 \times 10 \mathrm{~min}$ at RT) and counterstained with propidium iodide $\left(5 \mu \mathrm{g} / \mathrm{ml}, 10 \mathrm{~min}\right.$ at $37^{\circ} \mathrm{C}$ in AB-Diluent from Dako) and rinsed again in PBS (3 x 10 min at RT). Slides 
were viewed after mounting in Mounting Medium (Dako Diagnostica, Wien, Austria) and viewed at the confocal laser scanning microscope LSM510 Meta (Zeiss). Settings were the same as for BrdU-uptake.

\section{Membrane integrity}

\section{Lactate dehydrogenase release}

The CytoTox-ONETM Homogeneous Membrane Integrity Assay (Promega, Mannheim, Germany) was used according to the instructions given by the producer and fluorescence recorded with an excitation wavelength of $560 \mathrm{~nm}$ and an emission wavelength of $590 \mathrm{~nm}$. After subtraction of the blank value the average fluorescence from the samples was normalized to the maximum $\mathrm{LDH}$ release (lysis control).

\section{Adenylate kinase release}

The detection was carried out using ToxiLight BioAssay Kit (Lonza, Köln, Germany) according to the instructions given by the producer. Luminescence was read after 5 min on a luminometer (Lumistar, BMG Labtech).

\section{Propidium iodide uptake}

Cells were treated in chamber slides. After treatment, $10 \mu 11 \mathrm{mg} / \mathrm{ml}$ propidium iodide (Invitrogen) (final concentration $5 \mu \mathrm{g} / \mathrm{ml}$ ) was added to the culture medium for 10 min. Walls from the chamber slides were removed and the slides rinsed in PBS ( 3 x 10 min at RT), mounted in Mounting Medium (Dako Diagnostica) and viewed at the confocal laser scanning microscope LSM510 Meta (Zeiss). Images were acquired with excitation at $543 \mathrm{~nm}$ and detection with a LP 560 filter.

\section{Oxidative stress}

Cells were treated with subtoxic concentrations of particles and positive control (hydrogen peroxide, $\mathrm{H}_{2} \mathrm{O}_{2}$ ) to exclude an influence of the signal by cell loss.

\section{Oxidation of dehydroethidium}

Generation of radicals was evaluated after $4 \mathrm{hr}$ and $24 \mathrm{hr}$ in the presence of $10 \mu \mathrm{M}$ dihydroethidium (DHE) (Invitrogen) and PS particles or 50-200 $\mu \mathrm{M} \mathrm{H}_{2} \mathrm{O}_{2}$ in cell culture medium. Cells were either treated in chamber slides for microscopy or in cell culture plates for evaluation in the fluorometer. After the treatment cells were washed with PBS. Walls from the chamber slides were removed, mounted in Mounting Medium (Dako Diagnostica) and viewed by a fluorescence microscope. Fluorescence in the plates was read with $544 \mathrm{~nm}$ excitation and $612 \mathrm{~nm}$ emission at a fluorometer.

\section{Oxidation of dichlorodihydrofluorescein}

Cells were grown for $24 \mathrm{hr}$ in cell culture plates and loaded with $10 \mu \mathrm{M}$ 2,7-dichlorodihydrofluorescein diacetate (Invitrogen) in medium for $30 \mathrm{~min}$ at $37^{\circ} \mathrm{C}$. Subsequently, cells were rinsed and cultured for $4 \mathrm{hr}$ and $24 \mathrm{hr}$ with PS particles or $50-200 \mu \mathrm{M} \mathrm{H}_{2} \mathrm{O}_{2}$ as positive control. Fluorescence was read with $485 \mathrm{~nm}$ excitation and 520 $\mathrm{nm}$ emisssion at a fluorometer.

\section{Co-localization studies with organelles}

For co-localization studies cells were seeded in chamber slides and incubated with $25 \mu \mathrm{g} / \mathrm{ml}$ carboxyl Fluospheres in medium for $30 \mathrm{~min}$ and $24 \mathrm{hr}$. After this incubation, cells were labeled with the organelle trackers, which were all obtained from Invitrogen.

For labeling of the endoplasmic reticulum cells were washed twice first with medium $+10 \%$ FBS and secondly with HBSS and incubated with $1 \mu \mathrm{M}$ ER-Tracker Red (Bodipy TR glibenclamide) in HBSS for $20 \mathrm{~min}$ at $37^{\circ} \mathrm{C}$. Subsequently, cells were washed with HBSS and viewed under the microscope. For labeling of mitochondria, cells were rinsed twice in medium $+10 \%$ FBS and incubated with $200 \mathrm{nM}$ MitoTracker DeepRed 633 in complete medium for $20 \mathrm{~min}$ at $37^{\circ} \mathrm{C}$. After washing with complete medium cells were viewed.

For labeling of lysosomes cells were incubated with 50 nM Lyso Tracker Green DND 26 in complete medium. After $5 \mathrm{~min}$ of incubation at $37^{\circ} \mathrm{C}$ the cells were viewed under the microscope.

As marker for endosomes the receptor-mediated uptake of labeled transferrin as marker for early and recycling endosomes (Peters et al., 2001) was used. $25 \mu \mathrm{g} /$ $\mathrm{ml}$ Transferrin Conjugates Alexa Fluor 488 was added together with the particles and incubated for $30 \mathrm{~min}$ at $37^{\circ} \mathrm{C}$. Subsequently, the cells were rinsed three times in PBS, fixed in $4 \%$ paraformaldehyde, rinsed again in PBS and viewed.

Labeling of microtubules was performed by incubation of cells in $100 \mathrm{nM}$ TubulinTracker Green Reagent for Live-Cell Tubulin Labeling (OregonGreen 488Taxol, bisacetate) for $30 \mathrm{~min}$ at $37^{\circ} \mathrm{C}$. After three rinses in HBSS cells were viewed under the microscope.

Slides were viewed at the confocal laser scanning microscope LSM510 Meta (Zeiss). Images for co-localization of Fluospheres with Lyso Tracker Green DND and ER-Tracker Red were acquired at $488 \mathrm{~nm}$ excitation wavelength using a BP 505-530 nm band-pass detection filter for the green channel (Lyso Tracker, YG Fluospheres) and $543 \mathrm{~nm}$ excitation wavelength in conjunction with a LP $560 \mathrm{~nm}$ long pass filter for the red channel (ERTracker Red, red Fluospheres). Co-localization of YG 
Cytotoxicity of nanoparticles

Fluospheres with MitoTracker DeepRed 633 was viewed with $488 \mathrm{~nm}$ excitation and BP 505-530 nm detection for the Fluospheres and excitation at $633 \mathrm{~nm}$ in conjunction with detection at BP 679-754 nm for the MitoTracker.

For co-localization of red Fluospheres with Transferrin Alexa Fluor 488 and with Tubulintracker Green Reagent images were acquired at $488 \mathrm{~nm}$ and $543 \mathrm{~nm}$ excitation in conjunction with BP 505-530 nm and LP $560 \mathrm{~nm}$ filter, respectively.

\section{RESULTS}

\section{Physico-chemical properties}

Size and surface charge of the particles in the dynamic light scattering differed according to the medium in which they were suspended. In distilled water dispersion was best and smallest sizes were recorded. In medium $+5 \%$ FBS size for most particles was highest and surface charge was reduced. No difference was seen between particles in medium $+5 \%$ FBS and in medium $+10 \%$ FBS. The negative surface charge of carboxyl PS particles decreased with increasing concentrations of FBS in the medium. Amidine PS particles lost positive surface potential already in medium without FBS. For overview see Table 1.

\section{Cytotoxicity screening}

For screening and mode of action studies the EAhy 926 cell line was used. This cell line is derived from human umbilical vein endothelial cells and retains endothelial features to a high degree (Edgell et al., 1983; Unger et al., 2002). $20 \mathrm{~nm}$ carboxyl and carboxylate-modified PS particles, which are more hydrophilic according to the producer, showed similar cytotoxic action in the screening assays and the fluorescently labeled carboxyl PS particles showed the same cytotoxicity profile as the not labeled ones. All other particles, carboxyl PS particles $\geq$ $40 \mathrm{~nm}$ and amidine PS particles, did not show indication for cytotoxicity.

In the EAhy926 endothelial cell line the sensitivity of the different screening assays was compared. For comparison the half maximal inhibitory concentration $\left(\mathrm{IC}_{50}\right)$ as measure for the effectiveness of a compound in inhibiting biological or biochemical process was chosen. The $\mathrm{IC}_{50}$ of the ATP-content was at a concentration of $125 \mu \mathrm{g} / \mathrm{ml}$ $20 \mathrm{~nm}$ carboxyl PS (Fig. 1a). $\mathrm{IC}_{50}$ values in Neutral Red uptake, formazan bioreduction, sulforhodamine-B staining and leucine uptake assays ranged between 120 and $150 \mu \mathrm{g} / \mathrm{ml}$ upon this treatment. Results from these spectroscopic and radiometric screening assays were consistent with microscopical evaluation of calcein AM/ethidium homodimer staining (Fig. 1c). Table 2 shows that all viability screening assays used in this study produced very similar results.

The presence of $1 \%$ FBS in the medium reduced the cytotoxic effect of $20 \mathrm{~nm}$ carboxyl PS particles only slightly: in the formazan bioreduction assay for instance $\mathrm{IC}_{50}$ values increased from $150 \mu \mathrm{g} / \mathrm{ml}$ in medium without FBS to $250 \mu \mathrm{g} / \mathrm{ml}$ in medium with $1 \% \mathrm{FBS}$. At $5 \%$ and $10 \% \mathrm{FBS}$ in the medium size of the particles increased (see Table 1) and cytotoxicity decreased markedly. $20 \mathrm{~nm}$ carboxyl PS particles at $500 \mu \mathrm{g} / \mathrm{ml}$ decreased viability to $70 \%$ and $80 \%$, in medium with $5 \%$ and $10 \%$ FBS, respectively.

Table 1. Hydrodymamic diameter and sizes in different media of PS particles used in this study

\begin{tabular}{|c|c|c|c|c|c|c|c|}
\hline Functionalization, size & $\begin{array}{c}\text { Size in } \\
\text { distilled water } \\
(\mathrm{nm})\end{array}$ & $\begin{array}{l}\text { Size (DMEM, } \\
0 \% \text { FBS, nm) }\end{array}$ & $\begin{array}{l}\text { Size (DMEM, } \\
1 \% \text { FBS, nm) }\end{array}$ & $\begin{array}{l}\text { Size (DMEM, } \\
5 \% \text { FBS, nm) }\end{array}$ & $\begin{array}{c}\text { zeta-Pot. } \\
\text { (DMEM, 0\% } \\
\text { FBS, mV) }\end{array}$ & $\begin{array}{l}\text { zeta-Pot. } \\
\text { (DMEM, 1\% } \\
\text { FBS, mV) }\end{array}$ & $\begin{array}{c}\text { zeta-Pot. } \\
\text { (DMEM, 5\% } \\
\text { FBS, mV) }\end{array}$ \\
\hline Carboxyl modified, $20 \mathrm{~nm}$ & 24 & $35 / 110$ & $40 / 180$ & $45 / 120$ & -30.0 & -15.9 & -10.3 \\
\hline Carboxyl, $20 \mathrm{~nm}$ & 26 & $42 / 300 *$ & $35 / 250 *$ & 77 & -41.2 & -13.6 & -11.6 \\
\hline Carboxyl, $40 \mathrm{~nm}$ & 34 & $45 / 105^{*}$ & $40 / 176^{*}$ & 132 & -36.6 & -13.6 & -11.1 \\
\hline Carboxyl, $60 \mathrm{~nm}$ & 62 & $56 / 142 *$ & $81 / 210^{*}$ & 123 & -35.1 & -12.7 & -11.8 \\
\hline Carboxyl, $80 \mathrm{~nm}$ & 82 & 81 & 144 & 114 & -33.0 & -13.6 & -10.7 \\
\hline Carboxyl, $100 \mathrm{~nm}$ & 93 & 158 & 223 & 184 & -36.8 & -10.7 & -9.5 \\
\hline Carboxyl, $200 \mathrm{~nm}$ & 160 & 230 & 227 & 263 & -36.6 & -10.1 & -10 \\
\hline Amidine, $200 \mathrm{~nm}$ & 220 & $200 / 1922 *$ & $320 / 1050^{*}$ & $350 / 1150^{*}$ & -6.2 & -11.3 & -10.1 \\
\hline
\end{tabular}

*: two peaks in the size distribution recorded.

Abbreviations: FBS: fetal bovine serum; DMEM: Dulbecco's modified Eagle's medium. 
E. Fröhlich et al.
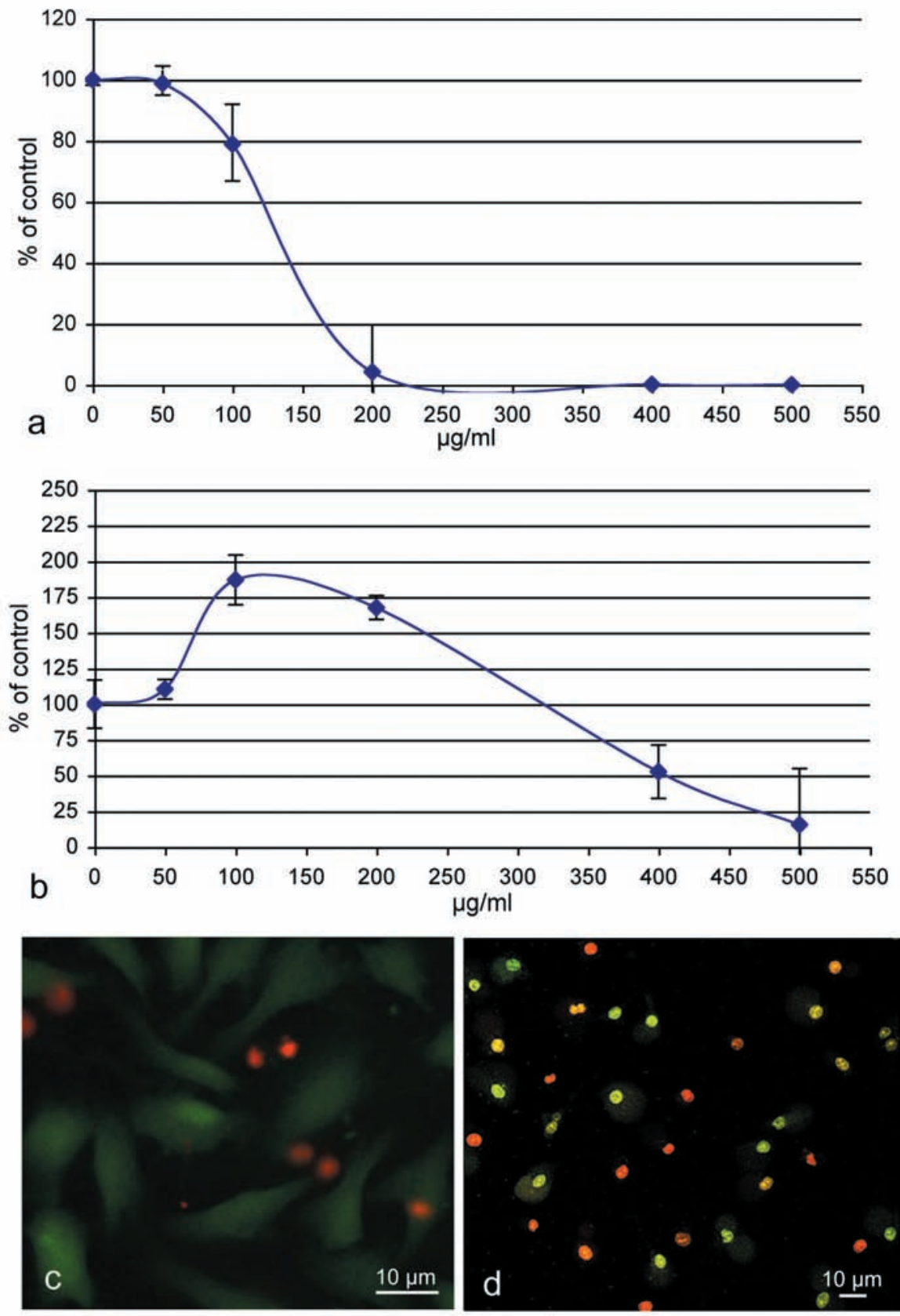

Fig. 1. Effect of $20 \mathrm{~nm}$ carboxyl PS particles after $24 \mathrm{hr}$ on EAhy926 cells regarding viability with ATP content (a) as parameter and in calcein AM/ethidium staining (c) and regarding apoptosis in terms of caspase 3/7 activation (b) and in YO-PRO-1/ propidium iodide co-staining $(\mathrm{d})$.

ATP content starts to decline at $100 \mu \mathrm{g} / \mathrm{ml}$ (a); at this concentration still more vital cells (green) than dead cells (red) are seen $(c)$.

Apoptosis in the caspase 3/7 activation is significantly increased at $100 \mu \mathrm{g} / \mathrm{ml}$ (b). Similar amounts of apoptotic cells (uptake of YO-PRO-1, green), of secondary apoptotic cells (uptake of both dyes, yellow) and of necrotic cells (incorporation of propidium iodide, red) are seen (d). 
Cytotoxicity of nanoparticles

Table 2. Sensitivity of screening assays for toxicity of 20 $\mathrm{nm}$ carboxyl PS spheres in the cell line EAhy926 after $24 \mathrm{hr}$ of exposure. For comparison $\mathrm{IC}_{50}$ values are given.

\begin{tabular}{lcc}
\hline Name of the assay & Principle & $\mathrm{IC}_{50}(\mu \mathrm{g} / \mathrm{ml})$ \\
\hline Formazan bioreduction & Metabolic activity & 150 \\
ATP content & Metabolic activity & 125 \\
Neutral Red uptake & Metabolic activity & 120 \\
Sulforhodamine B staining & Protein content & 120 \\
Leucin uptake & Protein content & 160 \\
\hline
\end{tabular}

\section{Mode of action}

\section{Apoptosis}

Caspase $3 / 7$ activation as indication for apoptosis was significantly increased at $100 \mu \mathrm{g} / \mathrm{ml}$ of $20 \mathrm{~nm}$ carboxyl PS particles (Fig. 1b). At this concentration similar amounts of apoptotic cells (uptake of YO-PRO-1, of secondary apoptotic cells (uptake of both dyes) and of necrotic cells (incorporation of propidium iodide) are seen (Fig. 1d). In the TUNEL staining, in contrast, only a minority of cells were labeled at $100 \mu \mathrm{g} / \mathrm{ml}$ and the fraction of TUNEL positive cells was higher at $200 \mu \mathrm{g} / \mathrm{ml}$. The fraction of cells showing fragmented cytokeratin 18 was highest at $100 \mu \mathrm{g} / \mathrm{ml}$, but the signal in general was low; at the maximum $50 \%$ of the cells were stained.

\section{Membrane damage}

LDH-release was significantly increased at $100 \mu \mathrm{g} /$ $\mathrm{ml}$ of $20 \mathrm{~nm}$ carboxyl PS particles (Fig. 2a). The release of adenylate kinase was not suited for the detection of membrane damage by carboxyl PS particles because no increase was recorded in the presence of these particles. Cells with disintegrated plasma membrane integrated propidium iodide into the DNA: intensely stained nuclei were seen upon exposure to $100 \mu \mathrm{g} / \mathrm{ml} 20 \mathrm{~nm}$ carboxyl PS particles (Fig. 2d). Propidium iodide positive cells contained a higher amount of fluorescently labeled (green) $20 \mathrm{~nm}$ carboxyl PS particles.

By the use of fluorescently labeled particles the correlation of uptake and membrane damage was studied: cells with a higher particle load in general showed propidium iodide uptake.

\section{Proliferation}

${ }^{3} \mathrm{H}$-thymidine uptake was significantly reduced already at $\geq 50 \mu \mathrm{g} / \mathrm{ml} 20 \mathrm{~nm}$ carboxyl PS particles (Fig. 2b). The reduction was confirmed by detection of BrdU-uptake in the presence and absence of carboxyl PS. At a concentration of $100 \mu \mathrm{g} / \mathrm{ml}$ only few cells with BrdU-uptake (d, green) were identified (Fig. 2d).

\section{Oxidative stress}

Cells were incubated with $20 \mathrm{~nm}$ and $200 \mathrm{~nm}$ carboxyl PS particles at sub-toxic concentrations of 0-100 $\mu \mathrm{g} / \mathrm{ml}$. Absolute signals in cells were markedly higher after 24 $\mathrm{hr}$ than after $4 \mathrm{hr}$ exposure but relative changes were similar. Incubation with dihydroethidium showed that few nuclei were stained in the controls (Fig. 3a) and particles of both sizes produced slightly higher but roughly similar increase in the incorporation of ethidium in the nuclei (Figs. $3 \mathrm{~b}$ and c). In the positive control $\left(100 \mu \mathrm{M} \mathrm{H}_{2} \mathrm{O}_{2}\right)$ all nuclei were stained (Fig. 3d). Detection of oxidative stress by oxidation of dichlorodihydrofluorescein produced similar results: both particles generated more fluorescence than untreated controls and much less than the positive control $\left(200 \mu \mathrm{M} \mathrm{H}_{2} \mathrm{O}_{2}\right.$, Fig. 3e $)$.

\section{Cell uptake and localization}

Uptake of PS particles was highest for $20 \mathrm{~nm}$ and lowest for $200 \mathrm{~nm} ; 500 \mathrm{~nm}$ particles were not taken up. Uptake rates were higher after $24 \mathrm{hr}$ than after $30 \mathrm{~min}$. To identify intracellular distribution of the particles and to find out if the smallest PS particles can penetrate into nucleus, mitochondria and endoplasmic reticulum a panel of organelle markers was used. Co-labelling (Figs. 4a and b) of 20, 40 and $200 \mathrm{~nm}$ PS spheres with transferrinAlexa 488 as marker for early and recycling endosomes (Peters et al., 2001) and with LysoTracker as marker for late endosomes and lysosomes was seen. No colocalization, however, of these particles with markers for endoplasmic reticulum and for mitochondria was recorded (Figs. 4c and d). $20 \mathrm{~nm}$ and $40 \mathrm{~nm}$ particles were associated to TubulinTracker positive structures (Figs. 4e and f). In time series it appeared that the particles were transported along these microtubules. Occasionally, $20 \mathrm{~nm}$ PS particles were seen in the nucleus.

\section{DISCUSSION}

This study on the cytotoxic mechanism of polystyrene particles revealed no difference in the generation of oxidative stress between $200 \mathrm{~nm}$ and $20 \mathrm{~nm}$ carboxyl PS particles $20 \mathrm{~nm}$ : carboxyl PS spheres induce cell damage while $200 \mathrm{~nm}$ particles did not. Carboxyl PS particles of $\geq$ $40 \mathrm{~nm}$ were not cytotoxic. $20 \mathrm{~nm}$ refers to the size of the particles in distilled water. In culture medium the PS particles were considerably larger. Earlier conclusions on the toxicity of nanoparticles were based on data originating 
E. Fröhlich et al.
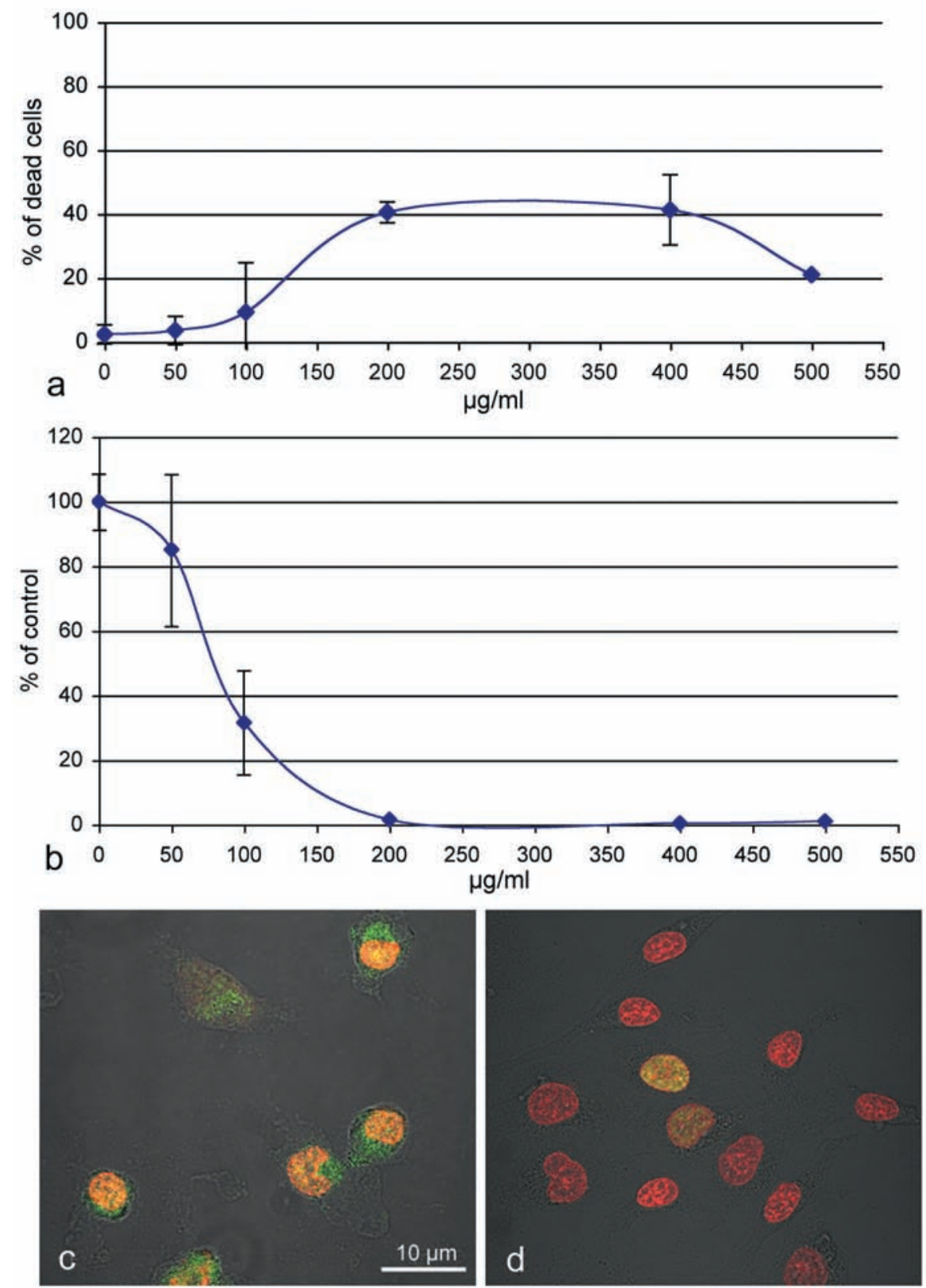

Fig. 2. Effect of $20 \mathrm{~nm}$ carboxyl PS particles after $24 \mathrm{hr}$ on EAhy926 cells regarding membrane damage demonstrated by lactate dehydrogenase release (a) and by propidium iodide uptake (c) and regarding proliferation assessed by ${ }^{3} \mathrm{H}$-thymidine uptake (b) and by BrdU-uptake (d).

At $100 \mu \mathrm{g} / \mathrm{ml} 20 \mathrm{~nm}$ Carboxyl PS particles LDH-release is significantly increased. Cells with disintegrated plasma membrane integrated propidium iodide (red) into the DNA. Propidium iodide positive cells contained a higher amount of fluorescently labeled (green) $20 \mathrm{~nm}$ carboxyl PS particles.

${ }^{3} \mathrm{H}$-thymidine uptake (b) was significantly reduced already at $\geq 50 \mu \mathrm{g} / \mathrm{ml}$. At a concentration of $100 \mu \mathrm{g} / \mathrm{ml}$ only few cells with BrdU-uptake (d, green) are seen. 

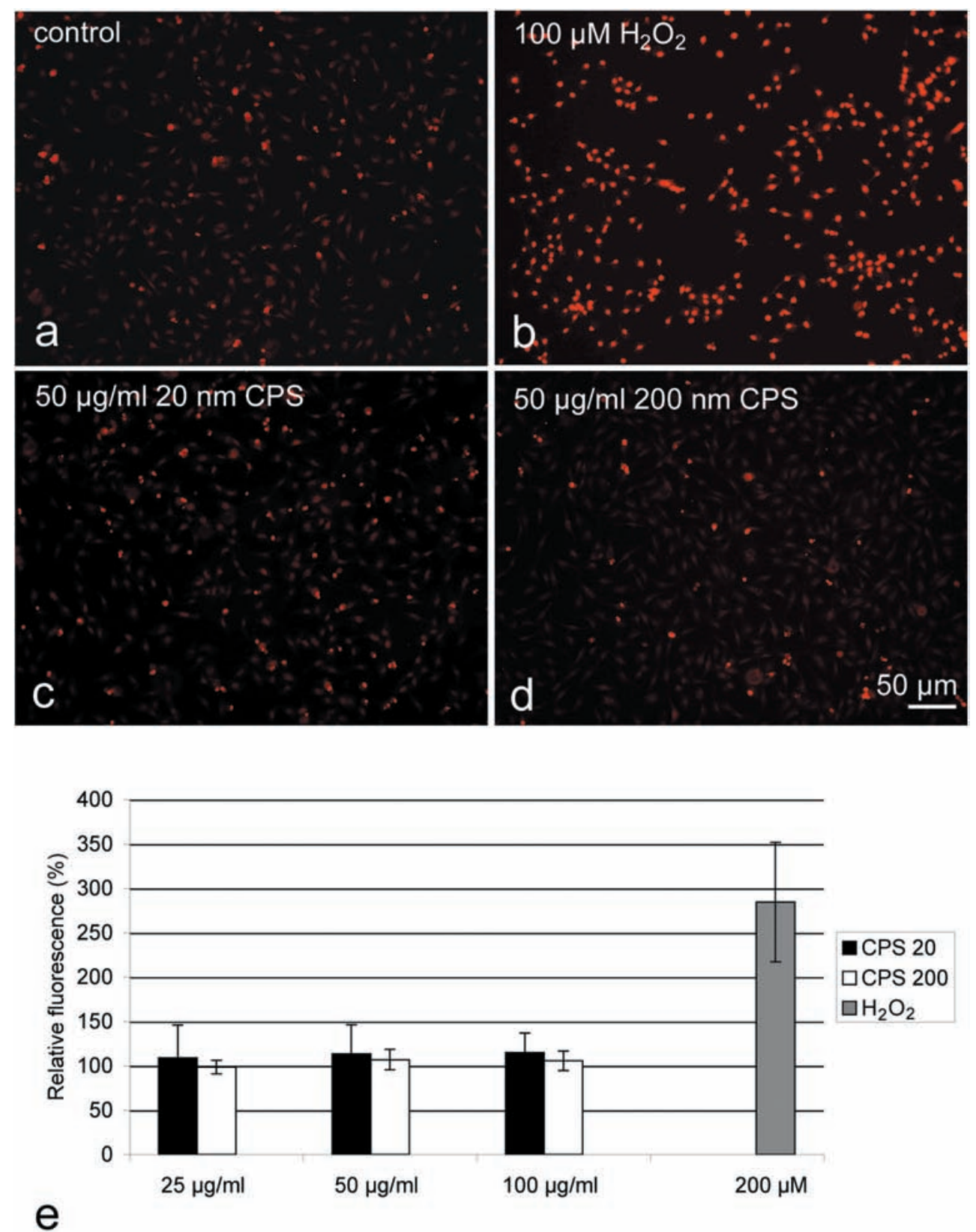

Fig. 3. Generation of oxidative species in EAhy 926 cells after exposure to $20 \mathrm{~nm}$ and $200 \mathrm{~nm}$ carboxyl PS particles assessed by oxidation of dihydroethidium (DHE) and by dichlorodihydrofluorescein (DCF). Cells treated with $50 \mu \mathrm{g} / \mathrm{ml}$ of $20 \mathrm{~nm}$ and $200 \mathrm{~nm}$ PS particles for $24 \mathrm{hr}$ (b and c) showed slightly more positive (red) nuclei than the untreated controls (a) and much less than in the positive $\left(\mathrm{H}_{2} \mathrm{O}_{2}\right.$-treated) control (d). e: Production of DCF is slightly enhanced in cells treated with PS particles but markedly less than in the positive $\left(\mathrm{H}_{2} \mathrm{O}_{2}\right.$-treated) control.

from dry particles or from suspensions in distilled water. More recently, changes induced by physiological media such as loss of surface charge and changes in size/aggregation were identified: particles such as carbon black, metal oxides and carbon nanotubes take advantage from a protein containing dispersion solution because their average size decreases (Bihari et al., 2008; Sager et al., 2007). These particles are more toxic in protein containing solu- 


\section{E. Fröhlich et al.}
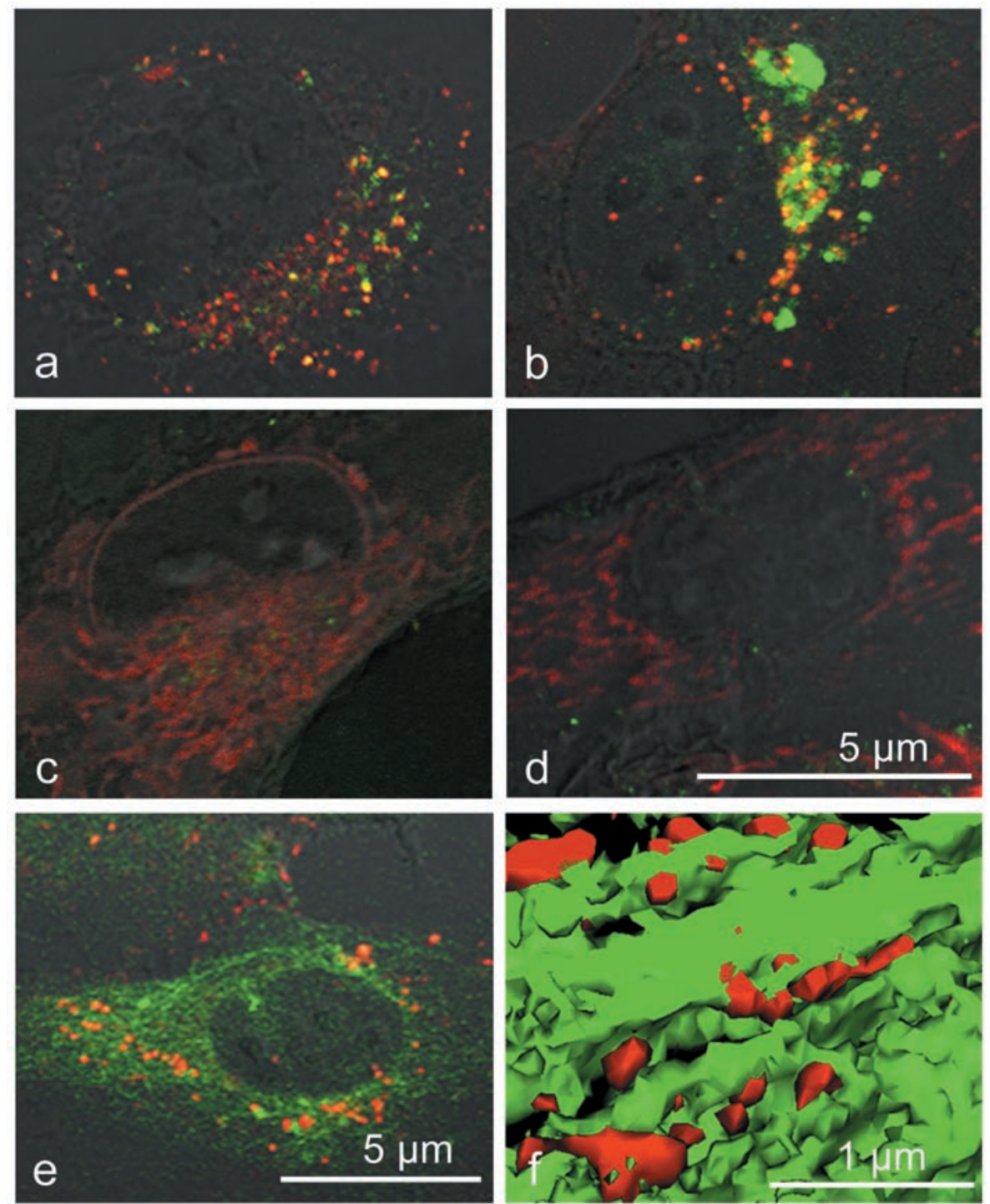

Fig. 4. Co-localization of organelle markers with $20 \mathrm{~nm}$ and $40 \mathrm{~nm}$ fluorescently labeled carboxyl PS particles in EAhy 926 cells. Carboxyl PS particles (red) of both sizes (40 nm particles shown) in part co-localize to transferrin-Alexa 488 positive structures (green) (a) and to lysosomes identified with Lysotracker (b). Co-localization is shown in yellow by merging of the red and green channel. Even the smaller $20 \mathrm{~nm}$ particles, however, were not seen in mitochondria or in the endoplasmic reticulum (c, d). Particles of both sizes ( $40 \mathrm{~nm}$ particles are shown) are seen in the vicinity of microtubules identified by Tubulin tracker green in the confocal image (e) and in the 3D reconstruction (f).

tions because the size of the aggregates is reduced. For PS particles an increase in toxicity is not seen because the average size increased in physiological solutions.

Increase in the size of dispersed PS particles most probably was due to aggregation and not caused by coating of the particles with protein. Coating with protein called corona formation and concomitant increase in the hydrodynamic diameter is seen for PS particles due to their hydrophobicity (Lundqvist et al., 2008). Bihari et al. (2008) reported that increases in size caused by corona formation with serum albumin typically causes increases in dynamic light scattering of $14.5 \mathrm{~nm}$ corresponding to 2 molecules of serum albumin. On the other hand, neutralization of the surface charge by salts or proteins favors the formation of aggregates. This effect caused larger increases than coating: sizes of $60 \mathrm{~nm}$ amine and amidine 
Cytotoxicity of nanoparticles

PS particles are 5-6 times larger in medium with FBS than in distilled water (Xia et al., 2006). $20 \mathrm{~nm}$ particles in our study were 2-4 times larger in physiological solutions suggesting the presence of aggregates.

For the assessment of the mode of cytotoxic action various assays were used. This was done firstly because some assays could have a lower sensitivity and therefore the effect would be obvious only at higher concentrations of particles. Secondly, interactions of nanoparticles with assay systems have been reported (Wörle-Knirsch et al., 2006) and should be identified. In general, no marked differences in the sensitivities of the assays were seen and interaction with the assay was rare and seen only for the luminescent detection of adenylate kinase release. This indicates that interferences can also occur in the absence of color and reductive or oxidative activity of the tested particles.

Not cationic PS microparticles or nanoparticles generally are regarded as non-toxic. Down to sizes of $60 \mathrm{~nm}$ PS particles did not induce cell damage in not phagocytotic cells and in-vivo (Olivier et al., 2003; Schöler et al., 2000; Silva et al., 2005). In our study we also found that $60 \mathrm{~nm}$ PS particles did not cause cell damage. The $20 \mathrm{~nm}$ PS particles, however, acted cytotoxic. Consistent with earlier studies (Swain et al., 2004) we did not detect prominent generation of oxidative stress. Although the level of oxidative species in cells treated with PS particles was higher than in un-treated cells, there was no significant difference between the generation by the cytotoxic $20 \mathrm{~nm}$ PS particles and the non-cytotoxic $200 \mathrm{~nm}$ PS particles.

Caspase activation and lactate dehydrogenase release were noted at concentrations lower than decrease in viability. We, therefore, conclude that disturbance of membrane integrity may be one mechanism for the cytotoxic action in PS nanoparticles.

Functionalized gold particles and nanotubes are able to cause holes in the plasma membrane by lipid peroxidation (Panessa-Warren et al., 2008). Polyamine-terminated dendrimers cause holes or enlarge holes in plasma membranes; the formation of such holes appears to be linked to cellular uptake of particles (Leroueil et al., 2007). For the uptake of polystyrene particles into erythrocytes adhesive and diffusive mechanism were proposed (Geiser et al., 2005). PS particles can bind a variety of proteins and, therefore, an interaction of the PS particles and binding of membrane proteins is likely. As plasma membrane contains attached and integrated proteins (Nelson and Cox, 2004) accounting for about $50 \%$ of the total plasma membrane this binding may disrupt the plasma membrane integrity. We observed that cells with membrane damage, identified by propidium iodide staining, contained more particles than cells with integer membrane.

It has been suspected that cellular uptake correlates with cell damage (Hong et al., 2006), which is consistent with our observation that $20 \mathrm{~nm}$ PS particles, which were cytotoxic, were taken up to a higher degree than 200 $\mathrm{nm}$ ones, which were not cytotoxic. PS particles of sizes $\geq 200 \mathrm{~nm}$ were taken up to a low degree as shown in other studies. Kato et al. (2003) reported that un-coated $240 \mathrm{~nm}$ PS particles are taken up by macrophages but not by endothelial cells. $80 \mathrm{~nm}$ and $200 \mathrm{~nm}$ PS particles are also taken up by erythrocytes whereas $1 \mu \mathrm{m}$ large particles are not (Geiser et al., 2005). For fibroblasts PS particle uptake up to $500 \mathrm{~nm}$ has been reported (Olivier et al., 2003). Despite a lower uptake rate of $200 \mathrm{~nm}$ PS particles compared to $20 \mathrm{~nm}$ particles in our study the subcellular distribution of both particles was essentially similar and the majority of the particles was seen in the endosomal compartment, which is consistent with the localization of other PS particles reported by other groups (Panyam et al., 2002). We did not see any co-localization with markers for ER and mitochondria for particles of both sizes.

The access to other organelles is size-dependent: Not targeted $9 \mathrm{~nm}$ in contrast to $30 \mathrm{~nm}$ gold nanoparticles have been detected in the nucleus (Berry et al., 2007). Targeted gold nanoparticles, however, transverse the nuclear core complex up to $39 \mathrm{~nm}$ of size (Panté and Kann, 2002) and polimide-coated core-shell silica nanoparticles in non-cytotoxic concentrations were seen in the nucleus even at a size of $66 \mathrm{~nm}$ (Fuller et al., 2008). We observed $20 \mathrm{~nm}$ sized PS particles in the nucleus only rarely. For the endoplasmic reticulum the size exclusion is $13 \mathrm{~nm}$ (Chang et al., 2008) and for mitochondria $3 \mathrm{~nm}$ (Salnikov et al., 2007) but particles causing cell damage by generation of oxidative stress are seen in mitochondria until larger sizes like fine $(<2.5 \mu \mathrm{m})$ and ultrafine $(<0.15$ $\mu \mathrm{m})$ ambient particles, which are seen inside structurally damaged mitochondria (Li et al., 2003). In view of these dimensions it is not surprising that the PS particles, which were tested at sub-toxic concentrations, were seen neither in mitochondria nor in the endoplasmic reticulum. Due to technical limitation of confocal microscopy the presence of single PS particles in these organelles cannot be excluded.

It can be concluded that nanoparticles can also damage cells by mechanisms not correlated to the generation of oxidative stress. These mechanisms may include induction of apoptotic and necrotic cell death and decreased proliferation. The pattern is not unique for PS particles but resembles for instance the one described for un-loaded chitosan particles (Qi et al., 2005). The signalling cas- 
cades, which are involved in these processes, have to be studied in more detail.

\section{ACKNOWLEDGMENTS}

This work was supported by the FP6 European integrated project "Nanobiopharmaceutics", NMP4-CT2006-026723 and the Austrian Science Fund grant N 214NAN.

\section{REFERENCES}

Berry, C.C., de la Fuente, J.M., Mullin, M., Chu, S.W. and Curtis, A.S. (2007): Nuclear localization of HIV-1 tat functionalized gold nanoparticles. IEEE Trans Nanobioscience, 6, 262-269.

Bihari, P., Vippola, M., Schultes, S., Praetner, M., Khandoga, A.G., Reichel, C.A., Coester, C., Tuomi, T., Rehberg, M. and Krombach, F. (2008): Optimized dispersion of nanoparticles for biological in vitro and in vivo studies. Part. Fibre Toxicol., 5 , 14.

Boas, U., Christensen, J.B. and Heegaard, P.M.H. (2006): Dendrimers in Medicine and Biotechnology: New Molecular Tools. RSC, Cambridge.

Brown, D.M., Wilson, M.R., MacNee, W., Stone, V. and Donaldson, K. (2001): Size-dependent proinflammatory effects of ultrafine polystyrene particles: a role for surface area and oxidative stress in the enhanced activity of ultrafines. Toxicol. Appl. Pharmacol., 175, 191-199.

Chang, M.Y., Shiau, A.L., Chen, Y.H., Chang, C.J., Chen, H.H. and Wu, C.L. (2008): Increased apoptotic potential and dose-enhancing effect of gold nanoparticles in combination with single-dose clinical electron beams on tumor-bearing mice. Cancer Sci., 99, 1479-1484.

Demoy, M., Gibaud, S., Andreux, J.P., Weingarten, C., Gouritin, B. and Couvreur, P. (1997): Splenic trapping of nanoparticles: complementary approaches for in situ studies. Pharm. Res., 14, 463468.

Edgell, C.J., McDonald, C.C. and Graham, J.B. (1983): Permanent cell line expressing human factor VIII-related antigen established by hybridization. PNAS USA, 80, 3734-3737.

Fernandez-Urrusuno, R., Fattal, E., Porquet, D., Feger, J. and Couvreur, P. (1995): Evaluation of liver toxicological effects induced by polyalkylcyanoacrylate nanoparticles. Toxicol. Appl. Pharmacol., 130, 272-279.

Fuller, J.E., Zugates, G.T., Ferreira, L.S., Ow, H.S., Nguyen, N.N., Wiesner, U.B. and Langer, R.S. (2008): Intracellular delivery of core-shell fluorescent silica nanoparticles. Biomaterials, 29, 1526-1532.

Geiser, M., Rothen-Rutishauser, B., Kapp, N., Schürch, S., Kreyling, W., Schulz, H., Semmler, M., Im Hof, V., Heyder, J. and Gehr, P. (2005): Ultrafine particles cross cellular membranes by nonphagocytic mechanisms in lungs and in cultured cells. Environ. Health Perspect., 113, 1555-1560.

Gibaud, S., Demoy, M., Andreux, J.P., Weingarten, C., Gouritin, B. and Couvreur, P. (1996): Cells involved in the capture of nanoparticles in hematopoietic organs. J. Pharm. Sci., 85, 944-950.

Hong, S., Hessler, J.A., Banaszak Holl, M.M., Leroueil, P.R., Mecke, A. and Orr, B.G. (2006): Physical Interactions of Nanoparticles with Biological Membranes: The Observation of Nano- scale Hole Formation. J. Chem. Health Saf., 13, 16-20.

Kanai, M., Murata, Y., Mabuchi, Y., Kawahashi, N., Tanaka, M., Ogawa, T., Doi, M., Soji, T. and Herbert, D.C. (1996): In vivo uptake of lecithin-coated polystyrene beads by rat hepatocytes and sinusoidal endothelial cells. Anat. Rec., 244, 175-181.

Kato, T., Yashiro, T., Murata, Y., Herbert, D.C., Oshikawa, K., Bando, M., Ohno, S. and Sugiyama, Y. (2003): Evidence that exogenous substances can be phagocytized by alveolar epithelial cells and transported into blood capillaries. Cell Tissue Res., 311, 47-51.

Leroueil, P.R., Hong, S., Mecke, A., Baker, J.R., Jr., Orr, B.G. and Banaszak Holl, M.M. (2007): Nanoparticle interaction with biological membranes: does nanotechnology present a Janus face? Acc. Chem. Res., 40, 335-342.

Lewinski, N., Colvin, V. and Drezek, R. (2008): Cytotoxicity of nanoparticles. Small, 4, 26-49.

Li, N., Sioutas, C., Cho, A., Schmitz, D., Misra, C., Sempf, J., Wang, M., Oberley, T., Froines, J. and Nel, A. (2003): Ultrafine particulate pollutants induce oxidative stress and mitochondrial damage. Environ. Health Perspect., 111, 455-460.

Limbach, L.K., Wick, P., Manser, P., Grass, R.N., Bruinink, A. and Stark, W.J. (2007): Exposure of engineered nanoparticles to human lung epithelial cells: influence of chemical composition and catalytic activity on oxidative stress. Environ. Sci. Technol., 41, 4158-4163.

Lundqvist, M., Stigler, J., Elia, G., Lynch, I., Cedervall, T. and Dawson, K.A. (2008): Nanoparticle size and surface properties determine the protein corona with possible implications for biological impacts. PNAS USA, 105, 14265-14270.

Nel, A., Xia, T., Mädler, L. and Li, N. (2006): Toxic potential of materials at the nanolevel. Science, 311, 622-627.

Nelson, D.L. and Cox, M.M. (2004): Lehninger Principles of Biochemistry. Palgrave Macmillan Ltd., Hampshire.

Nemmar, A., Hoylaerts, M.F., Hoet, P.H., Dinsdale, D., Smith, T., $\mathrm{Xu}, \mathrm{H}$., Vermylen, J. and Nemery, B. (2002). Ultrafine particles affect experimental thrombosis in an in vivo hamster model. Am. J. Respir. Crit. Care Med., 166, 998-1004.

Olivier, V., Duval, J.L., Hindié, M., Pouletaut, P. and Nagel, M.D. (2003): Comparative particle-induced cytotoxicity toward macrophages and fibroblasts. Cell Biol. Toxicol., 19, 145-159.

Pan, Y., Neuss, S., Leifert, A., Fischler, M., Wen, F., Simon, U., Schmid, G., Brandau, W. and Jahnen-Dechent, W. (2007): Sizedependent cytotoxicity of gold nanoparticles. Small, 3, 1941-9.

Panessa-Warren, B.J., Warren, J.B., Maye, M.M., van der Lelie, D., Gang, O., Wong, S.S., Ghebrehiwet, B., Tortora, G.T. and Misewich, J.A. (2008): Human epithelial cell processing of carbon and gold nanoparticles. Int. J. Nanotechnol., 5, 55-91.

Panté, N. and Kann, M. (2002): Nuclear pore complex is able to transport macromolecules with diameters of about $39 \mathrm{~nm}$. Mol. Biol. Cell, 13, 425-434.

Panyam, J., Zhou, W.Z., Prabha, S., Sahoo, S.K. and Labhasetwar, V. (2002): Rapid endo-lysosomal escape of poly(DL-lactide-coglycolide) nanoparticles: implications for drug and gene delivery. FASEB J., 16, 1217-1226.

Papageorgiou, I., Brown, C., Schins, R., Singh, S., Newson, R., Davis, S., Fisher, J., Ingham, E. and Case, C.P. (2007): The effect of nano- and micron-sized particles of cobalt-chromium alloy on human fibroblasts in vitro. Biomaterials, 28, 2946-2958.

Park, E.J., Choi, J., Park, Y.K. and Park, K. (2008): Oxidative stress induced by cerium oxide nanoparticles in cultured BEAS-2B cells. Toxicology, 245, 90-100.

Peters, P.J., Gao, M., Gaschet, J., Ambach, A., van Donselaar, E., 
Cytotoxicity of nanoparticles

Traverse, J.F., Bos, E., Wolffe, E.J. and Hsu, V.W. (2001): Characterization of coated vesicles that participate in endocytic recycling. Traffic, 2, 885-895.

Qi, L.F., Xu, Z.R., Li, Y., Jiang, X. and Han, X.Y. (2005): In vitro effects of chitosan nanoparticles on proliferation of human gastric carcinoma cell line MGC803 cells. World J. Gastroenterol., 11, 5136-5141

Rejman, J., Oberle, V., Zuhorn, I.S. and Hoekstra, D. (2004): Sizedependent internalization of particles via the pathways of clathrin- and caveolae-mediated endocytosis. Biochem. J., 377, 159169.

Sager, T.M., Porter, D.W., Robinson, V. A., Lindsley, W.G., Schwegler-Berry, D.E. and Castranova, V. (2007): Improved method to disperse nanoparticles for in vitro and in vivo investigation of toxicity. Nanotoxicology, 1, 118 - 129.

Salnikov, V., Lukyánenko, Y.O., Frederick, C.A., Lederer, W.J. and Lukyánenko, V. (2007): Probing the outer mitochondrial membrane in cardiac mitochondria with nanoparticles. Biophys. J., 92, 1058-1071.

Schöler, N., Zimmermann, E., Katzfey, U., Hahn, H., Müller, R.H. and Liesenfeld, O. (2000): Effect of solid lipid nanoparticles (SLN) on cytokine production and the viability of murine peritoneal macrophages. J. Microencapsul., 17, 639-650.

Semmler-Behnke, M., Kreyling, W.G., Lipka, J., Fertsch, S., Wenk, A., Takenaka, S., Schmid, G. and Brandau, W. (2008): Biodistribution of 1.4- and 18-nm gold particles in rats. Small, 4, 2108-
2111.

Silva, V.M., Corson, N., Elder, A. and Oberdörster, G. (2005): The rat ear vein model for investigating in vivo thrombogenicity of ultrafine particles (UFP). Toxicol. Sci., 85, 983-989.

Swain, W.A., O'Byrne, K.J. and Faux, S.P. (2004): Activation of p38 MAP kinase by asbestos in rat mesothelial cells is mediated by oxidative stress. Am. J. Physiol. Lung Cell Mol. Physiol., 286, L859-865.

Unger, R.E., Krump-Konvalinkova, V., Peters, K. and Kirkpatrick, C.J. (2002): In vitro expression of the endothelial phenotype: comparative study of primary isolated cells and cell lines, including the novel cell line HPMEC-ST1.6R. Microvasc. Res., 64, 384-397.

Wörle-Knirsch, J.M., Pulskamp, K. and Krug, H.F. (2006): Oops they did it again! Carbon nanotubes hoax scientists in viability assays. Nano Lett., 6, 1261-1268.

Xia, T., Kovochich, M., Brant, J., Hotze, M., Sempf, J., Oberley, T., Sioutas, C., Yeh, J.I., Wiesner, M.R. and Nel, A.E. (2006): Comparison of the abilities of ambient and manufactured nanoparticles to induce cellular toxicity according to an oxidative stress paradigm. Nano Lett., 6, 1794-1807.

Yacobi, N.R., Demaio, L., Xie, J., Hamm-Alvarez, S.F., Borok, Z., Kim, K.J. and Crandall, E.D. (2008): Polystyrene nanoparticle trafficking across alveolar epithelium. Nanomedicine, 4, 139145. 
